\author{
Natàlia Cugueró-Escofet
}

Josep M. Rosanas 


\title{
LEADERSHIP, ETHICS, PRUDENCE AND JUSTICE: PRUDENCE ALONE IS NOT ENOUGH FOR DECISION-MAKERS
}

\author{
Natàlia Cugueró-Escofet ${ }^{1}$ \\ Josep M. Rosanas ${ }^{2}$
}

\begin{abstract}
It is not unusual for management researchers to take the view that value judgements and thus virtues make for an unrealistic approach to management because what is considered realistic is achieving specific results; and these may be easier to obtain in the short run if managers follow some rules based not on morality but on 'facts' (i.e., empirical relationships between quantitative results and the actions taken).

We argue that, on the contrary, virtues are crucial for competent decision-making, mainly if we take a dynamic, long run view of the organization. We then analyze virtues, knowledge and the relationship between them, to show the interrelationships between prudence, practical wisdom and justice. We argue that the unity of virtues, while a desirable end, may have to be acquired through practice and that, for that purpose, justice has to be the main priority. Justice will then help to develop prudence and, with the other virtues incorporated as well, provide a better future for the organization in all its aspects.
\end{abstract}

JEL Classification: 131, M14, M15

Keywords: Prudence, justice, fairness, virtue ethics, practical wisdom.

\footnotetext{
${ }^{1}$ Professor UOC (Open University of Catalonia)

${ }^{2}$ Professor, Financial Management, PricewaterhouseCoopers Chair of Finance, IESE
} 


\section{LEADERSHIP, ETHICS, PRUDENCE AND JUSTICE: PRUDENCE ALONE IS NOT ENOUGH FOR DECISION-MAKERS}

\section{Introduction}

In a recently published book, Pfeffer (2015) argues that what he calls "leadership BS" is often preached in books and articles about leadership on the (supposedly empirical) basis that what most 'successful' leaders do is the complete reverse of what is demanded of them in the academic literature. According to Pfeffer, what is recommended in the literature is based on 'morality' and having a good relationship with coworkers/employees but what real-world leaders actually do is often immoral.

Pfeffer's attitude is fairly common among management researchers in two respects. First, in that his view is that the basic criterion for decision-making should be short-term effectiveness, which is reflected mainly in the accounting numbers and at most in other highly visible variables. The reason, of course, is that this is what investors, the media, the general public, even some academics and maybe some business executives value. And second, Pfeffer, like most academics, prefers to avoid 'value judgments' on whether something is good or bad because value judgments are considered 'unscientific.' More or less explicitly, the idea behind this is that Pfeffer's approach is a 'realistic' approach while 'BS' analyses are not: that it is obvious that managers should base their decisions on facts instead of on values.

As we will show, we disagree, first because many researchers have shown other variables related to ethics to be important (e.g., Cugueró-Escofet and Rosanas, 2013), and second because unethical decision-making has unfavorable effects, at the very least in the long run. And the purpose of this paper is essentially to discuss the role of virtues in managerial decision-making and the relative importance of each.

This type of discussion has taken place in economics before. McCloskey $(2006,2008)$ has argued that prudence only (or, rather, the " $P$ variables," according to her, which include prudence) is not good enough. Other variables, like the $\mathrm{S}$ variables (solidarity, society, speech...) and the $O$ variables (concerns for justice, the secular parts of love, and the self-sacrificing parts of courage) should be considered too: the $S$ and the 0 variables are not (and should not be) strangers to economics. However, McCloskey never tries to be specific in terms of the practical application of these concepts in the real world of business.

In this paper, we attempt to complement McCloskey's work by taking the management point of view, and we intend to be more operational in the sense of showing how the $S$ and 0 variables" 
can be developed. For this purpose, we limit ourselves to prudence and justice, in the belief that the analysis can naturally be extended to other virtues.

A (rather restrictive) concept of prudence often found in everyday language is that of avoiding unnecessary risks. This concept can be very effective in proposing ways to minimize risk but doing this alone can be very inefficient for promoting organizations where managers seek to create value in the long run. In this respect, prudence alone may create more problems than it can solve.

We have to go well beyond that to have a meaningful concept of prudence that can be considered a virtue and that may include the previous concept as a particular (and simplistic) case. For that purpose, the concept of prudence in decision-making should be that of appropriately balancing all the consequences of an alternative action, weighing up the desired and the undesired consequences, in a way that reflects the decision-maker's personality, goals and concept of well-being.

The evolution through time of such variables is a key point in our analysis, and (implicitly) bounded rationality is another key point. If economic agents in organizations had unbounded rationality and could foresee all contingencies and deal with the corresponding uncertainty in a strictly rational way, there would be no problems in making choices. All conceivable alternatives would be available and, being able to foresee all contingencies and therefore all results, decisionmakers would make all their choices with no problems (and, of course, instantaneously). In contrast, with bounded rationality only the prudent person will give appropriate weight to desirable consequences in the future, compared with the not-so-desirable consequences that will take place right away.

Developing prudence has to do with learning. For a decision-maker who is 'alone,' making decisions that affect only himself, like Robinson Crusoe, trial and error on the one hand and choosing prudent actions on the other would develop prudence in the individual (Aristotle). However, in an organization that is acting in a market, there are other people involved, mainly employees and customers. In that case, prudence alone is not enough. At least, whatever actions are taken, they also have to be just for all the individuals involved.

In many traditional models, justice is often seen as a sufficient condition for prudence but this does not mean that it is also a necessary condition. Actually, we can find situations where there is prudence but not justice. In such situations, people may put up with unjust decisions that are regarded as the lesser of two evils, asserting that the prudence or effectiveness of the decision justifies the unfairness of the results.

In other approaches, prudence is considered a sufficient condition for justice, which means that, if a decision is prudent, then it is just. The contrapositive statement (logically equivalent to the original one) is therefore that an unjust decision is imprudent. In contrast, we want to show in this paper that, since it is perfectly possible for a decision to be both unjust and prudent, hard choices have to be made. The time dimension is therefore crucial, and justice has to be the dominant criterion in the short run. The effects of injustice on people are so important that, in the short run, it is better for decision-makers themselves to be imprudent rather than unjust. Again, the ideal situation is to be both prudent and just, of course, but this may be difficult to achieve, and some decision-makers may settle for a decision that is prudent but unjust.

We will proceed as follows. First, we will review the concept of unity of virtue and the basic Aristotelian virtues applied to management, to see how they interrelate and the types of knowledge needed to develop them. Practical wisdom is of course a crucial concept here. Then we will focus on prudence and justice to show that justice should be the priority for an 
organization to develop correctly, achieving greater prudence and reaching the ideal state of being prudent and just at the same time.

\section{Unity of virtue and empirical evidence}

Classical Greek philosophers considered the unity of virtue as a fact and a normative proposition as well. They thought that a virtuous person should possess all the moral virtues at once. Aristotle attempts to refute the idea that all virtues can "exist in separation from each other" and that "the same man, it might be said, is not best equipped by nature for all the virtues, so that he will have already acquired one when he has not yet acquired another. This is possible in respect of the natural virtues, but not in respect of those in respect of which a man is called without qualification good" (Aristotle 2000, Book VI).

However, empirical evidence appears to contradict this idea, for it can be seen easily that virtues may function separately from each other. That is, a person can be courageous but dishonest or just but lazy. In general there are alternative proposals on the unity of virtue thesis, depending on whether their proponents argue for a unity of virtues in a stronger or in a weaker sense (Wolf, 2007). Wolf argues that we can consider virtues united weakly in terms of the knowledge involved - that is, "the kind of knowledge that, on this view, is necessary for true virtue is knowledge of what is important or worthwhile. [...] the kind of knowledge in question is the kind we have in mind when we describe someone as having her priorities straight” (Wolf, 2007, p. 14).

Therefore, to understand virtues' unity or lack thereof, it seems essential to understand which knowledge is important and how this knowledge is linked to virtues and the process by which human beings acquire them. However, all virtues could affect all the professions, so there is no clear link between a profession and a virtue, as there are many professions that allow a person to live a virtuous life but this is perfectly compatible with the view that acquiring some specific virtues could be more crucial in one profession than in another, specifically in the so-called natural dispositions that people have from their childhood (Wolf, 2007).

Here we are concerned with the management profession, so we are going to focus the discussion as much as possible on managers, their decisions, their acts and the virtues that affect them. We are also concerned with realistic empirical evidence of finding situations where virtues may not all be attainable in the short run at the same time, so there is room for considering that a virtuous person can start by focusing more on one virtue and then acquiring the others. We argue that

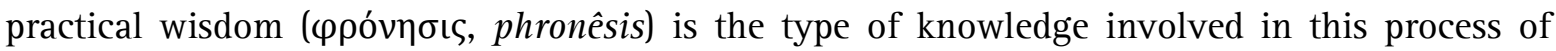
acquisition, "for with the presence of one quality, practical wisdom, will be given all the virtues" (Aristotle 2000, Book VI). Aristotle, however, does not say how practical wisdom intervenes in the specific process of acquisition we are going to set out here. We also try to show all the other types of knowledge involved, and how they intervene and develop what we think is a virtuous manager and so a good one.

Of course it seems reasonable to agree that the ideal is to possess all virtues at once (a perfect state of affairs, in which we embrace all the virtues and each one reinforces the other) but here we are concerned with a more realistic situation in business in which choosing in the short term which virtue should be dominant seems a reasonable (and we might even say mandatory) and realistic approach. 


\section{Virtues in management}

In management, it is important to see whether the unity of virtues is necessary in the full sense or whether we need what Wolf calls a "weak" concept of it. If we take a look at reality, it is easy to conclude that managers face situations in which being perfectly virtuous (i.e., holding all the virtues in all possible situations), would seem to be a superhuman endeavor. When managers face a situation and need to decide and act, they would need to see how to be prudent, just to all parties, courageous and generous and to do the same for all the virtues that seem relevant for the people affected and involved. We agree that knowing how to be prudent involves knowing the value of the money involved in the transaction and in the alternative courses of action, and the risk for all parties posed by these alternatives, as well as knowing on which aspects it is worth spending money, taking risks, etc. And the same applies to the rest of the virtues we have listed above.

However, take the case of justice and prudence. It could very well be that, in the short run, being prudent and just in a specific situation is practically impossible, so the manager needs to establish priorities about which virtue is the one that may be neglected in the short run but that it is possible to attain in the long run.

Some definitions of prudence already involve this prioritizing. The proponents of these concepts can argue that the decision to neglect prudence in the short run is prudence in the full sense. However, we think that this prioritizing, which in Aristotle's words has been understood as "practical wisdom" (a concept that we will examine later on) is more of a judgment and so part of the virtue of justice that is everywhere, with justice itself being a virtue rather than only part of prudence. We are going to show that practical wisdom potentially affects all virtues and is the element that allows the short run to be taken care of in order to prioritize one virtue over the other, to make the full attainment of virtues possible in the long run.

In the literature we can find arguments to show that practical wisdom is an important quality for a manager who has to make a problematic decision in order to be virtuous (Roca, 2007). This practical wisdom is concerned with evaluative knowledge - that is, being able to judge whether a specific action is worthwhile. This leaves open the question of whether there is only one type of virtue at the beginning of all business situations or whether this would be a situational factor whereby the virtue with which the manager starts is always dependent on the specific circumstances the manager faces - which is evaluative knowledge as well but of a more general type.

There is abundant literature showing that the consequences of neglecting specific virtues are not harmless and that the lack of some virtues may produce tough managerial consequences that can damage the business activity. For instance, this is the case with neglecting justice (Bies and Tripp, 1995; Gilliland et al., 2002; Martin, 1993; Tepper, 2001), which shows the importance of managing justice and injustice in the workplace (Cropanzano et al., 2007; Reb et al., 2006). Also, there is empirical literature on management showing that the consequences of neglecting specific virtues are different from the consequences of neglecting others. This strictly depends on the different stakeholders involved: prudence is more concerned with the business activity as a whole and so it has consequences for the shareholders' wealth, whereas injustice seems to affect the workforce more directly in most situations. Of course, having a demotivated workforce may create many harmful effects on future operations, which in turn would imply a loss of shareholder value.

However, going beyond the empirical evidence, there are other types of research that discuss the relative importance of several virtues in terms of specific areas of knowledge. It is important to look into the consequences of the absence of a virtue to see that these consequences are not the 
same, depending on the combination of virtues, and for that reason care must be taken regarding which virtue may be crucial at the beginning.

We have already mentioned that knowledge is a relevant aspect related to virtues. For that reason we are going to analyze the importance of knowledge and which different types of knowledge are involved in virtues. We will also analyze which types of knowledge are involved in the process of starting with one virtue while possibly acquiring the rest later.

\section{Knowledge, action and virtue}

Virtue and knowledge are intimately related, as we have already mentioned. One of the promoters of the unity of virtues, Susan Wolf, has proposed a weak unity of virtues that functions through the knowledge, mainly evaluative, involved in acquiring them (Wolf, 2007). Aristotle argues that each virtue involves knowledge and specifically the evaluative knowledge concerned with what is important in terms of that virtue (Aristotle, 2000, Book VI). The golden mean (each virtue being in the middle of two nonvirtuous extremes) implies an element of evaluative knowledge and therefore good judgment, which is a rational element, something that only human beings can possess. This specific knowledge has been given several names (judgment, rational intelligence, practical wisdom, among others) and is involved in making decisions about things that vary in nature, are unpredictable to a large degree and require some degree of personal experience. Of course, in the case of the law, to be just it is necessary to follow just laws but this is not enough. People need judgment to make a decision on a particular application of the law, even if the law is no longer just. Thus, following the rules rigidly will not guide the behavior of a just person, as justice has no virtue that can resist it when a specific and strict policy is followed in all situations. The knowledge that we are interested in - the kind that affects virtues - is comparative in nature. It involves two things - "having a sense of how much of one good is worth risking or sacrificing for another, but also understanding when and for what kinds of goods different kinds of action are appropriate" (Wolf, 2007, p. 23). So, "knowledge of the values especially important to the possession of one virtue will thus necessarily involve knowledge of the values important for the possession of the others" (Wolf, 2007, p. 23).

According to Aristotle, the "states by virtue of which the soul possesses truth by way of

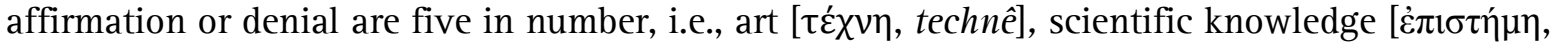

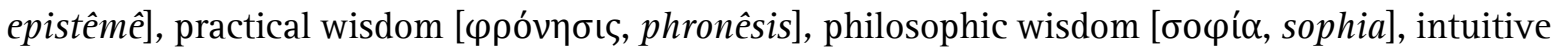
reason [voũ, nous]" (Aristotle, 2000, Book VI). The one related to modern theoretical knowledge is epistêmê, while technê can be considered a craft, an art or a set of skills. The first knowledge is scientific while the second is practically oriented. In the sphere of management, practical knowledge is of course relevant, even if it is not sufficient as we will see. Here we need to consider action and virtue, so we have to go one step further from the knowledge involved in technê. Technê is related to the knowledge involved in creating objects, and we also need the knowledge involved in taking action. The Aristotelian view is that craft is different from virtue: in craft, some end or product is obtained after the 'making,' whether or not virtue leads to a virtuous action, so the agent needs to act by following a disposition of character. The value of the action, therefore, depends on the agent.

In addition to those two states, two others are relevant for our purposes: phronêsis and nous. These are very important because both involve experience to make it possible to acquire virtues in the 
long run (Hursthouse, 2006). Intuitive reason or nous is crucial as it is the virtue involved in grasping the first principles from which scientific knowledge follows (Aristotle, 2000, Book VI).

Epistêmê and technê are mixed in many situations: in any profession that is involved with practical matters, some knowledge is relevant as well, and the professional needs to possess it in order to be good at the profession. In the next part, we are going to revise thoroughly the main conceptual approaches to justice and prudence, two of the virtues that have been extensively applied to management (i.e., organizational justice, in the area of organizational behavior). However, we are going to review them also as they relate to practical wisdom because we are interested in understanding the acquisition of virtues and the role of practical wisdom as a way to prioritize one virtue over the rest to assist managers in decision-making processes.

Phronêsis or practical wisdom is a type of knowledge that is acquired through practice. Practical wisdom is an appreciation of reality, of the cause-effect relationships that help us to solve problems that are not fixed, not yet determined by the existing knowledge of cause-effect relationships. Thus, existing knowledge or sophia - which is the sum of nous and epistêmê - is not enough. People need to start learning this practical knowledge by acquiring personal experience or through the experience of others. (In this case, this experience can be real, such as the advice of an experienced manager, or it can be simulated by formal instruction, such as the case method.) When people acquire practical wisdom through their own experience, they run the risk of learning the wrong thing. This would make practical wisdom deteriorate as people would attribute the wrong causes to certain effects, which would only make things worse for future decisions.

\section{Prudence and practical wisdom (phronêsis)}

Prudence is the virtue that allows a person to act according to the knowledge about which means are necessary in a given decision - which in a complex decision involves practical wisdom (Aristotle, 2000, Book VI). This is therefore an intellectual virtue but by itself it is not a guide to behavior because it is necessary to incorporate the reason (or end) of that decision (which incidentally also involves people's motives).

Prudence in management has been equated with simplistic views about incorporating only aspects that can be measured - what Deirde N. McCloskey labels " $P$ variables." These aspects consist mainly of prudence related to prices and profits, meaning that a prudent decision must foresee prices and profits and avoid as much as possible the risks of a loss, forgetting about other, greater ends that are included in the " $O$ variables" and the " $S$ variables" (McCloskey 2006, 2008). Sen distinguishes between "well-being" and "agency" - the former being the notion that appears in the utility function, and the latter the ability to form goals, commitments and values (Amartya Sen, 1987). Therefore, the " $P$ variables" are means, not ends, and so "the agency is to be understood, far beyond means, as the ability and the desire to form goals" (McCloskey, 2008, p. 181). In other economic approaches, Maximum Utility man is seen as an "automaton [...] with no internal quarrels and no dilemmas" (Lipka, 2013), so this is a model of man that can serve as a tool to decide simple things that require purely preset and well-established knowledge and therefore is not useful for complex and real decisions, as is the case with managers. However, the real prudent man requires some self-command, with a definition of prudence that includes some "loose, vague, and indeterminate rules" that instruct the prudent man "to avoid risk" (Lipka, 2013, p. 8). Of course, rules of prudence are not categorical imperatives, as there is also the need to 
balance whether or not they are appropriate to a specific situation. Also, once he has the knowledge, a prudent man needs to be willing to behave accordingly.

This concept of prudence found in the economics literature is rather restrictive. In essence, it means avoiding unnecessary risks. However, doing this alone can be very inefficient for promoting organizations where managers seek to create value in the long run. In this respect, prudence alone may create more problems than it can solve if, while behaving according to prudence, managers forget other virtues. We have to go well beyond that to have a meaningful concept of prudence that can be considered a virtue and that may include the former concept as a particular (and simplistic) case. For that purpose, the concept of prudence in decision-making should be that of appropriately balancing all the consequences of an alternative action, weighing up the desired and the undesired consequences, in a way that reflects the decision-maker's personality, goals and concept of well-being. This would incorporate practical wisdom, which is the type of knowledge that we have already explained. This practical wisdom has been taken to be equivalent to prudence in some cases, even if prudence requires a willingness to act according to all knowledge involved in a decision, not only the knowledge of practical wisdom.

Next, we are going to examine practical wisdom and its relation to prudence and how other virtues, such as justice, must be included when other significant ends are desired, when other people are involved and affected by the decision (MacIntyre, 2007; McCloskey, 2006).

As stated above, some researchers in philosophy regard prudence and practical wisdom as being practically the same. However, prudence is a virtue of character (which requires will), whereas practical wisdom was considered by Aristotle as one of the types of knowledge that involves understanding the right goals to attain while applying the other types of knowledge to make a good decision about what to do (Aristotle, 2000, Book VI). In management, prudential decisionmaking has been considered practically equivalent to decision-making using practical wisdom (Roca, 2007).

However, here we are interested in showing several reasons for considering both as different aspects of the virtue spectrum. First, not separating the concepts of prudence and practical wisdom makes it impossible to consider that we can have one of them without the other, which can very well be the case. Situations can be found in which there may be prudence but there is no complete use of practical wisdom. There are many definitions of prudence that include references to avoiding risks and dealing with uncertainty and that can entail good judgment to a greater or lesser extent (and therefore wisdom to a greater or lesser extent). The opposite is also true - we can also find practical wisdom without prudence. We can think of situations in which people have developed a degree of practical knowledge even if they are not willing to act accordingly and so do not practice it. Perfectly wise people understand what to do in the fullest sense but can only practice a partial form of prudence, either because they are not willing to act according to the decision made in theory or because they have a degree of prudence without being totally wise practically.

Second, practical wisdom, in our view, is related to the knowledge involved in all virtues regarding means but also, and more importantly, ends and so it is not linked exclusively to the virtue of prudence. If we look at how practical wisdom is defined, it also indicates the means necessary to attain a more important moral virtue, which is justice. Tiberius and Swartwood explain that "practical wisdom illuminates the nature of a right action, which leads to a focus on the wise person as a perfect judge of what to do" (Tiberius and Swartwood, 2011, p. 278). In this definition, practical wisdom incorporates also the knowledge about ends, in which the virtue of 
justice is necessary. For someone to be considered just, this person must incorporate a specific form of practical wisdom, even more intensively than for a prudent person. This person must look at the different aspects and balance them to decide which one to incorporate when making a decision in order to lead to a good decision. We will examine this more carefully in the next part of this paper, developing the concepts of practical wisdom (as a form of knowledge) and justice (as one of the three moral virtues).

Third, practical wisdom, and wisdom in general, can be defined in several ways. Depending on the definition, it needs a broad set of requirements that go well beyond a single virtue and that allow us to consider the idea that virtue, incorporating the knowledge of the wise, can be a true virtue. (Of course it ultimately needs a willingness to act accordingly but at least it has the ingredients to be a true virtue.) Definitions of practical wisdom incorporate four elements: deep understanding, reflective capacities, problem-solving capacities, and specific motivations to live well and help others live well (Tiberius and Swartwood, 2011).

Fourth, there is a crucial component involved in a wise person, as "the motivation to help others to choose well is implied by the fact that a wise person provides guidance to others and has a concern for others" (Tiberius and Swartwood, 2011, p. 283). Thus, this fourth element motivation to help others - can be an element that characterizes more virtues than solely prudence. For instance, as we will see, this element can be seen more clearly when we consider the virtue of justice, which incorporates caring for the results that affect all parties in a decision. And finally, practical wisdom is a kind of knowledge, so to reach the category of virtue of character one needs to care enough about the ends to be attained - for instance, being just and caring that justice is generated, which makes the person morally just.

\section{Justice and practical wisdom}

Practical wisdom and justice have not been linked generally to management, directly, but many references can be found that connect the two virtues. Justice as a moral virtue, in its fullest sense, incorporates individual judgment of what the right thing to do is, and how to incorporate and balance the different elements to be included in a decision about what to do. This is revealed when practical wisdom is used in the decision, so practical wisdom is the type of knowledge that is necessary and a just person needs to incorporate the knowledge of practical wisdom.

Of course, it is possible to be just but not completely wise, so practicing justice with practical wisdom is what makes people practice the virtue of justice, and so possibly attain the ideal of being just. In this respect, this is similar to prudence but the connection between justice as a moral virtue and practical wisdom as an intellectual virtue is even stronger. The definition of practical wisdom incorporates an element of justice. It is possible to be prudent (with respect to some rules of prudence that are practiced consistently) but not completely wise (or to have a conception of practical wisdom limited to means and not to the ultimate ends of a decision).

In the short run, it seems much more difficult to be considered wise if someone is unjust, while being wise and imprudent can be accepted when the reason for this is linked implicitly to greater ends, involved in justice creation. "A person with practical wisdom needs the capacity to judge what is at stake and what is at stake from the perspective of the relevant parties" (Tiberius and Swartwood, 2011, p. 285). This argument is aligned with the Aristotelian argument that justice is the mother of all virtues and that this reflection involves judging and balancing the perceptions of reality with our normative frameworks and updating these frameworks if there are relevant 
reasons to do so (Cugueró-Escofet and Fortin, 2014). Learning how to manage means learning how to be just, because people update their perceptions of justice as they look at managers and companies with respect to how able these are when it comes to creating justice. On the other hand, prudence is concerned mainly with the means. It is practical wisdom involved with the means in the sense of attaining prudence and is also practical wisdom involved with the means (rules of justice) and with the ends (attaining a just decision for the parties involved). Therefore, we need practical wisdom concerned with the "habit of mind whereby one is excellent in each case at finding the available means to accomplish a worthy end" (Beabout, 2012, p. 427). This worthy end is not informed by or balanced using prudence but justice.

\section{Prudence, justice and practical wisdom}

Of course, proponents of equating prudence and practical wisdom would say that being wise is being prudent. And we can partially agree - being wise now and tomorrow requires being virtuous in general, so in the end to be considered a wise person means being prudent and just at the same time (and of course, not only prudent and just - all possible moral virtues need to be incorporated for someone to be considered wise). Even if prudence is an intellectual virtue, that of being willing to use the rational part of a person's being, some propose prudence as the fourth cardinal moral virtue because it is fed by elements of the ends and it is necessary to reach decisions that create moral consequences. We think that moral virtues incorporate also a part that transcends mere self-control, a part that uses self-control to improve not only ourselves but also others. (Here justice creation, justice avoidance and injustice reparation are crucial aspects that have been seen in management as relevant for all stakeholders involved in companies.) We partially agree with this concept of prudence but only for dealing with situations in which both virtues are present. However, this concept of prudence cannot explain how to reach this perfect situation from situations in which one of the virtues is not totally present in the short run. For that reason, we separate both virtues. We present prudence as the intellectual virtue that ponders the means and leads to those means that are useful in a given situation - detached from justice, which is concerned about the means and the ends that are desired to attain in the long run. We think that, by presenting prudence in this way, we are able to show which virtue is the best to use when starting, in order to achieve excellence, in which all virtues must be involved.

However, we are interested in the process of acquiring these virtues, not assuming that we have both at the same time. Instead, some assumptions for guiding behavior decide from which one of the two it is preferable to start. If we connect wisdom with justice, we think that being just is crucial in the short run because it is never possible to be wise and unjust. Therefore, we can acquire wisdom through justice and then improve ourselves in terms of prudence, whereas this is unlikely if we start with prudence and injustice. If we are unjust we cannot be considered wise, as we are unable to ponder (judge) properly between several criteria from the beginning and determine the consequences of incorporating specific criteria or not. If we start being unjust, we lack from the beginning the necessary wisdom to avoid the consequences of an unjust decision. Therefore, we are unable to avoid unjust consequences in our decisions, which makes us incapable of progressing in the creation of further wisdom and of improving our prudence as a consequence.

Being completely wise would entail being just and prudent but we can start with the wisdom necessary to reach a just decision. Even if the wisdom is imprudent in the short run, it allows us to create a situation in which improvement in terms of wisdom is possible and therefore we can attain prudence in the long term. We cannot start from an unjust and prudent situation, as this 
would lack the short-term wisdom necessary to start the process. This minimum wisdom is the one that Sen considers makes it easier to avoid blatant injustices, compared with the wisdom we need for a positive prudent state, which would entail the creation of complete justice. In the end, we find it more difficult to agree on what is needed for an ideal world than agreeing from the beginning not to create a world that is not ideal (Sen, 2009). So, we are more compelled to understand and develop the wisdom that is necessary for a situation in which we can avoid the creation of injustice, accepting short-term imprudence and being duty bound to improve the actual imprudence, rather than developing a wisdom that ponders short-term prudence while being unjust and spreading the consequences of this injustice along the way. Following this argument, wisdom is a long-term goal that involves all virtues but not all of them are equally important in the short run. Justice is a means (through wisdom) and an end (creating an ideal of justice), while prudence can be considered an end (achieving a good decision-making process in the long run that can create justice). Next we will illustrate the combination of justice and prudence (both with the necessary knowledge of practical wisdom) and we will demonstrate with an example how a situation of "imprudent injustice avoidance" is easier to improve than a situation of "prudent injustice creation." We can see the four combinations in Table 1.

\section{Tabla 1}

Combinations of justice and prudence

\begin{tabular}{|c|c|c|c|}
\hline & & \multicolumn{2}{|c|}{ Justice } \\
\hline & & YES & NO \\
\hline \multirow{2}{*}{ Prudence } & YES & $\begin{array}{l}\text { Just prudential } \\
\text { decision-making }\end{array}$ & Prudent injustice creation \\
\hline & NO & $\begin{array}{c}\text { Imprudent injustice } \\
\text { avoidance (imprudent justice } \\
\text { creation) }\end{array}$ & Imprudent injustice creation \\
\hline
\end{tabular}

\section{The result: a dynamic evolution of prudence and justice}

When a specific situation needs to be resolved, managers should try to find an option that is completely virtuous and therefore just and prudent, which would be the ideal solution. However, it may well be that this option is not available in the short run.

It is not uncommon for many firms (and the authors of this paper have witnessed situations of this kind more than once) to find themselves in a situation where, on the one hand, with current activities, profitability is not bad but it is stagnating or even deteriorating. Then something has to be done to avoid future problems. Alternatively, management may simply want to grow. In any case, the firm examines possible alternatives for investment, perhaps in a foreign country. Typically, there is a physical investment, of course, but there is also an intangible investment, in terms of the business not being very profitable at the beginning, the appropriate workforce having to be trained, possibly having some expatriates in the management team of the foreign subsidiary. There is a lot of uncertainty associated with such investments, so making a decision is no trivial matter.

Practical wisdom is a type of knowledge that is indispensable when making a decision of this kind. The relevant variables are not easy to evaluate. A number of calculations can be made, based on accounting techniques, but then other variables of a qualitative nature have to be 
evaluated as well. For instance, the decision should contemplate the availability of qualified workers who are able to achieve the organization's goal, and others for the purpose of managing the organization. An organization that is successful should have a distinctive competence that is not easy to copy or imitate - perhaps in its (hard) technology, perhaps in how it handles the division of labor, perhaps in the way it is managed. In any case, it should have a character that defines the special way the organization makes the product or provides the service it sells.

Practical wisdom means being able to put together all the relevant variables that are explicit and have been studied, predict what is likely to happen, given the uncertainties, and make a good choice. Thus, a decision-maker has to have some knowledge that goes beyond the scientific knowledge required and beyond the empirical knowledge of the world. That is what practical

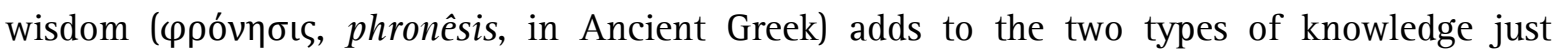
mentioned: some first-hand knowledge that has not been organized in terms of a branch of science and is not related to abilities acquired by human beings through experience. It is related to the ability to learn from experience in terms of making educated guesses as to what variables are going to be relevant, predicting possible results that are not so obvious and putting all these elements together so that a decision can be made as rationally as possible. The product of all this is an alternative way of acting that looks reasonable overall.

The virtue of prudence, then, means being able to put all of this analysis into practice. This would depend on the rules of prudence used in that situation and some personal judgment related to the knowledge of practical wisdom. To incorporate justice, we need to use aspects of practical wisdom concerning justice, as well as other aspects linked to other types of knowledge involved in the virtue of justice as a moral end in itself.

Going back to our example, suppose that, in that process, an alternative of starting a subsidiary in a distant foreign country has been developed. The alternative is workable and promises to be profitable in the future but at the beginning it will not be. Therefore, funds will have to be transferred from the parent company. Moreover, in order to start the new venture in that country, the know-how that the parent company possesses has to be used to start the new company and, for that purpose, the firm needs to take some of the good professionals in the parent company to work in the subsidiary. The salaries of people going there will have to be substantially higher than the salaries at home and very likely the operations there will be less efficient, in the beginning at least.

Therefore, there appear to be many problems with the new investment, which will have to be evaluated using practical wisdom. We are simplifying things here but it is easy to imagine the amount of detail that will have to be taken into account - mainly about the employees of the new subsidiary, and the uncertainties associated with the new market and with demand. Practical wisdom, from this point of view, may recommend that the investment be undertaken, and top management, exercising the virtue called prudence, may decide to go ahead. Doing so may be a prudent decision but is it just?

The answer is that it might well not be just for the people affected, mainly if (as quite often happens) employees in the subsidiary are better paid than employees in the parent company, largely because (1) the parent company is subsidizing the subsidiary, (2) the salaries at the subsidiary are higher, and (3) any performance index of the parent company gives better results than those of the subsidiary.

Then we have two virtues in conflict. The alternative of not investing in the subsidiary may be imprudent, given the assessment made by management of the firm's future prospects. However, 
continuing with the investment would create an unjust situation for the employees of the parent company and for the entity as a whole because the subsidiary receives better treatment as an organizational unit than the parent organization. Going ahead with the investment in the conditions outlined may thus create a situation that is prudent but unjust and will very likely be perceived as unfair by the employees. This situation, from the top management's point of view, is likely to remain stable. The only pressure for change will come (perhaps) from the employees who think they are being treated unfairly but this may not happen at all and the employees may leave the firm, creating a situation that is likely to become imprudent. (The best employees are the ones who can find better jobs more easily.)

What are the alternatives to that situation? An obvious alternative is not to make the investment, which creates a situation that may be just but imprudent, in the sense that the parent company may decline steadily and perhaps even disappear eventually. Therefore, management is under pressure to do something because sooner or later it will become obvious that the firm is declining or even in danger.

We can think of another alternative, which is to undertake the investment, but with compensation being paid to the parent company and its employees because of the unjust situation that the investment would create. This would of course increase costs and make the new investment less profitable, making the decision less prudent perhaps but more just. Again, management will feel the pressure to improve the situation from the point of view of prudence and thus to make it just and prudent in due course. In either of the last two alternatives, the situation is similar: imprudence will arise and represent a danger for top management and so efforts will be made to correct the situation. In the first alternative, an unjust situation puts less pressure on top management and therefore the situation can last for quite a long time (perhaps forever). Even where problems that are a consequence of the unjust situation emerge after a number of years (lower quality of employees, for instance), management and/or external observers may not attribute the problems to the unjust situation they created because, in the meantime, many other things may have happened (including changes in the environment) that can be blamed for the problems.

We can argue that choosing the option of "imprudent injustice avoidance" seems the most reasonable one as it forces managers to search actively for a solution for the imprudence generated and in a way that does not create more injustice or that can also generate justice. On the other hand, in the case of one of the "prudent injustice creation" situations, there is no pressure to find another solution and in general this situation continues over time with no pressure for change.

Only a just organization can be an organization where people are motivated by the organizational objectives. Thus, it may become an organization that has results that are above normal (perhaps only in the long run). The current emphasis on "strategy design" (Bower, 2008) in management courses misses that point. What we have attempted to do in this paper is precisely to show that a necessary condition for this to happen is that justice be emphasized from the beginning. Moreover, this will help to develop the other virtues (including prudence as a crucial element) and create an even better organizational climate. 


\section{Conclusions}

The purpose of this paper is, first, to argue that prudence alone is not the best approach for developing a virtuous environment in organizations and it will not help managers to tackle the major decisions they usually face. Then, we also argue that justice, in a wider sense, is also the best starting point of a dynamic process aimed at creating virtuous management.

If a manager focuses on prudence and allows injustice to exist in the short term, the manager is failing to include practical wisdom. In that case, prudence tends to be short-sighted and therefore the usual consequences of the decisions are forgotten in terms of a more crucial element: the justice generated for the recipients that in turn has effects on the organization's long-term effectiveness and efficiency.

In contrast, if a manager focuses on justice in the short term by incorporating the necessary practical wisdom, even if some imprudence is generated, the manager can avoid unfair consequences happening and improve the short-term imprudence, in order to reach a situation where there is long-term prudence. Being wise but unjust is not possible even in the short run, while it is possible to be wise and just in the short run, allowing for some imprudence, and to acquire wisdom along the way, gaining a deeper understanding of the consequences of decisions and achieving a state of practical wisdom with justice and prudence.

We have attempted to develop a more comprehensive version of realistic situations in management, in which the combination of prudence and justice makes justice more prevalent in the short run, so as to avoid injustice creation and its consequences. Therefore, we show that justice, in its facet of judgment, is the principal element that must be included in prudence, as justice is not only a requirement of prudence but must be considered as a desired output of any decisions. A decision that is prudent and unjust generates long-term imprudence, so it is undesirable. On the other hand, a decision that is just but may have some imprudence in the short run can be seen as generating justice and in the long term prudence can be achieved in practical managerial decision-making.

We propose a conceptual framework in which justice is shown to be a better starting point for achieving other virtues, as it allows decision-makers to be wiser. We show that when in the short run, there is no prudence but there is justice, prudence may be easily attained in the long run.. By entering a virtue-generating circle, managing with justice as the starting point makes it easier to achieve prudence than the converse. The organization then develops in a way that is desirable in itself and at the same time is likely to produce better results in the future, that would involve justice and prudence

We believe that this can be extended to other virtues that are important in organizations and management as well, but we started with these two as both have been studied extensively in decision-making and management. Hence, future research can also use this approach to look into other important virtues. 


\section{References}

Aristotle (2000). Nicomachean ethics. Translated by W. D. Ross. Internet Classics Archive by Daniel C. Stevenson. http://classics.mit.edu/Aristotle/nicomachaen.html.

Beabout, G. R. (2012). Management as a domain-relative practice that requires and develops practical wisdom. Business Ethics Quarterly 22(2), 405-432.

Bies, R. J. and Tripp, T. M. (1995). The use and abuse of power: Justice as social control. In R. Cropanzano and M. K. Kacmar (eds.) Organizational politics, justice, and support: Managing the social climate of work organizations. (pp. 131-145). Quorum Books, New York.

Bower, J. L. (2008). The teaching of strategy: From general manager to analyst and back again? Journal of Management Inquiry 17(4), 269-275.

Cropanzano, R., Bowen, D. E. and Gilliland, S. W. (2007). The management of organizational justice. Academy of Management Perspectives 21(4), 34-48.

Cugueró-Escofet, N. and Fortin, M. (2014). One justice or two? A model of reconciliation of normative justice theories and empirical research on organizational justice. Journal of Business Ethics 124(3), 435-451.

Cugueró-Escofet, N. and Rosanas, J. M. (2013). The just design and use of management control systems as requirements for goal congruence. Management Accounting Research 24(1), 23-40.

Gilliland, S. W., Steiner, D. D. and Skarlicki, D. P. (2002). Emerging perspectives on managing organizational justice. Information Age Publishing, Greenwich, CT.

Hursthouse, R. (2006). Practical wisdom: A mundane account. Proceedings of the Aristotelian Society 106, 285-309.

Lipka, D. (2013). The Max U approach: Prudence only, or not even prudence? A Smithian perspective. Econ Journal Watch 10(1), 2-14.

MacIntyre, A. (2007). After virtue, 3rd edition. University of Notre Dame Press, Notre Dame, IN.

Martin, J. (1993). Inequality, distributive injustice, and organizational illegitimacy. In J. K. Murnighan (ed.) Social psychology in organizations: Advances in theory and research (pp. 296-321). Prentice Hall, Englewood Cliffs, NJ.

McCloskey, D. N. (2006). The bourgeois virtues: Ethics of an age of commerce. University of Chicago Press, Chicago, IL.

McCloskey, D. N. (2008). Not by P alone: A virtuous economy. Review of Political Economy 20(2), 181-197.

Pfeffer, J. (2015). Leadership BS: Fixing workplaces and careers one truth at a time. HarperCollins, New York.

Reb, J., Goldman, B. M., Kray, L. J. and Cropanzano, R. (2006). Different wrongs, different remedies? Reactions to organizational remedies after procedural and interactional injustice. Personnel Psychology 59(1), 31-64. 
Roca, E. (2007). Introducing practical wisdom in business schools. Journal of Business Ethics 82(1), 607-620.

Sen, A. (1987). On ethics and economics. Blackwell, Oxford.

Sen, A. (2009). The idea of justice. Belknap Press, Cambridge, MA.

Tepper, B. J. (2001). Health consequences of organizational injustice: Tests of main and interactive Effects. Organizational Behavior and Human Decision Processes, 86(2), 197-215.

Tiberius, V. and Swartwood, J. (2011). Wisdom revisited: A case study in normative theorizing. Philosophical Explorations 14(3), 277-295.

Wolf, S. (2007). Moral psychology and the unity of the virtues. Ratio 20(2), 145-167. 